\title{
Multipurpose furnace for in situ studies of polycrystalline materials using synchrotron radiation
}

\author{
Hemant Sharma, ${ }^{1}$ Alix C. Wattjes, ${ }^{2}$ Murugaiyan Amirthalingam, ${ }^{3}$ Thim Zuidwijk, ${ }^{1, a)}$ \\ Nico Geerlofs, ${ }^{1}$ and S. Erik Offerman ${ }^{1, b)}$ \\ ${ }^{1}$ Department of Materials Science and Engineering, Delft University of Technology, Mekelweg 2, \\ 2628 CD Delft, The Netherlands \\ ${ }^{2}$ Electronic and Mechanical Support Division (DEMO), Delft University of Technology, Mekelweg 4, \\ 2628 CD Delft, The Netherlands \\ ${ }^{3}$ Materials Innovation Institute, Mekelweg 2, 2628 CD Delft, The Netherlands
}

(Received 26 August 2009; accepted 18 October 2009; published online 2 December 2009)

We report a multipurpose furnace designed for studies using synchrotron radiation on polycrystalline materials, namely, metals, ceramics, and (semi)crystalline polymers. The furnace has been designed to carry out three-dimensional (3D) x-ray diffraction measurements but can also be used for other types of synchrotron radiation research. The furnace has a very low thermal gradient across the specimen $\left(<0.2{ }^{\circ} \mathrm{C} / \mathrm{mm}\right)$. Accurate determination of the temperature can be carried out by welding a thermocouple to the specimen. The furnace can be rotated over an angle of $90^{\circ}$ in order to determine the crystallographic orientation of each individual grain. It is possible to follow growth kinetics of all grains in the illuminated volume of the specimen. The specimen environment can be controlled varying from vacuum (up to $10^{-5} \mathrm{mbar}$ ) to gas or air filled. The maximum temperature of operation is $1500{ }^{\circ} \mathrm{C}$, with the possibility of achieving high heating (up to $20^{\circ} \mathrm{C} / \mathrm{s}$ ) and cooling rates (up to $30{ }^{\circ} \mathrm{C} / \mathrm{s}$ without quenching gas). 3D maps of the microstructure of the specimen can be generated at elevated temperatures by bringing the high-resolution detector close to the specimen. We show an example of a simulation of the heat affected zone during the thermal cycle of a weld in a transformation-induced plasticity steel carried out using the furnace. The unique characteristics of the furnace open possibility of new fields in materials research using synchrotron radiation. (c) 2009 American Institute of Physics. [doi:10.1063/1.3262501]

\section{INTRODUCTION}

In recent years, high-energy $\mathrm{x}$-ray radiation, available at third generation sources such as the European Synchrotron Radiation Facility (ESRF) in Grenoble (France), the Advanced Photon Source in Argonne (USA), and Spring-8 in Nishi Harima (Japan), has become more and more important for studies in materials science. In particular for polycrystalline materials, $\mathrm{x}$-ray phase-contrast tomography (PCT), ${ }^{1,2}$ three-dimensional (3D) crystal microscopy, ${ }^{3,4}$ 3D x-ray diffraction (3DXRD) microscopy, ${ }^{5-8}$ and diffraction contrast tomography (DCT) ${ }^{9-11}$ have been used. PCT is a powerful technique to study material systems with an inhomogeneous density distribution, e.g., silicon particles can be visualized in cast aluminum alloys, ${ }^{1}$ but the crystal orientations cannot be determined. 3DXRD technique, developed jointly by scientists at ID11, ESRF, and RISØ, Denmark, in the 1990s, has shown to be a powerful tool for carrying out in situ studies in metals. The DCT technique can be considered a variant of 3DXRD. The 3DXRD technique allows for nondestructive characterization of grains in terms of volume, ${ }^{12}$ orientations, ${ }^{13}$ and stresses ${ }^{14}$ in bulk microstructures. The

\footnotetext{
${ }^{\text {a)} P r e s e n t ~ a d d r e s s: ~ D e p a r t m e n t ~ o f ~ I m a g i n g ~ S c i e n c e ~ a n d ~ T e c h n o l o g y, ~ D e l f t ~}$ University of Technology, Lorentzweg 1, 2628 CJ Delft, The Netherlands.

${ }^{b)}$ Author to whom correspondence should be addressed. Electronic mail: s.e.offerman@tudelft.nl.
}

experimental setup is rather similar to x-ray tomography, the difference being that in tomography, one probes the attenuation of the direct beam and reconstructs the density of the specimen. However, in 3DXRD, the diffracted signal from different crystalline grains is used to reconstruct the microstructure within the material. In this way, a 3D image of the microstructure can be obtained for materials without a density difference with micrometer resolution. In comparison, focused ion beam 3D electron back-scatter diffraction $(\mathrm{EBSD})^{15}$ has a better spatial resolution but, being a surface technique, is destructive and ex situ in nature, and the volumes that can be investigated are limited. In general, 3DXRD can be used in three modes. In fast mode, the characteristics of each grain (for example, volume, position of center of mass, and orientation information) can be obtained with a time resolution of the order of a few seconds. On the other hand, in slow mode, full 3D mapping of grain location, shape, and orientation can be carried out, with a mapping precision of $5 \times 5 \times 1 \mu \mathrm{m}^{3}$ but with a lower time resolution of the order of a few hours. In the high-resolution mode, deformation structures of the material can be investigated by placing the detector at a large distance from the specimen. ${ }^{14}$ The 3DXRD setup is shown in Fig. 1. In order to get all the grains under diffraction a number of times, the specimen is rotated around the vertical axis.

In the present paper we describe a furnace specially de- 


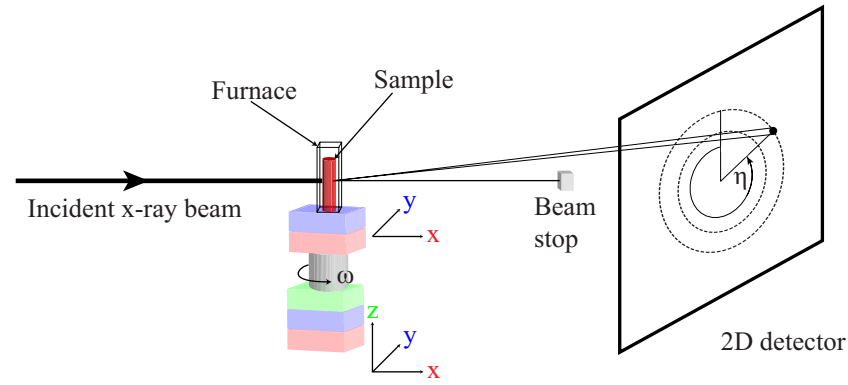

FIG. 1. (Color online) Schematic of the 3DXRD setup. Shown in the figure are the incident beam direction, location of the specimen and furnace around it, and the 2D detector to record diffraction patterns. During the experiment, specimen is rotated around the vertical axis over an angle $\omega$ in order to bring all grains into diffraction multiple times.

signed to carry out 3DXRD measurements at temperatures of up to $1500{ }^{\circ} \mathrm{C}$ while meeting all the requirements of the setup of 3DXRD technique. The furnace is suited for studies of polycrystalline materials including metals, ceramics, and semicrystalline polymers. Although the furnace was designed for 3DXRD experiments, it can as well be used for x-ray tomography and DCT in the low temperature mode (see Sec. VI for details). In addition, the furnace can also be used for other synchrotron radiation experiments such as highresolution powder diffraction and small angle x-ray scattering (SAXS). The furnace overcomes various shortcomings of other furnaces available for 3DXRD experiments. For example, while operating in the high temperature range, the specimen can be rotated over an angular range of $90^{\circ}$, as compared to a previous furnace reported by Margulies et al., ${ }^{16}$ in which rotation is limited to an angle of only $9^{\circ}$, which is not enough to bring all the grains under diffraction sufficient number of times in order to find out the crystallographic orientation of all grains. Also, the furnace of Margulies et al. cannot be used with the high-resolution detector due to geometrical constraints arising from the design of the detector. In comparison to that, the furnace reported by Bellet et al. ${ }^{17}$ has the advantage that, being a tomography furnace, it can be rotated over an angle of $360^{\circ}$. However, it suffers from the disadvantage that the maximum temperature that can be reached is $1030{ }^{\circ} \mathrm{C}$ and, because the specimen is heated directionally from the bottom, has a considerable thermal gradient across the specimen. Furthermore, the high temperature stability of the furnace of Bellet et al. is not long enough for full 3D mapping using the high-resolution detector, and there is no possibility to accurately determine the specimen temperature by welding a thermocouple to it. There are also other furnaces available for high temperature synchrotron experiments, for example, the furnace reported by Brokmeier et al., ${ }^{18}$ but they are not suited for 3DXRD measurements due to space and other constraints.

Section II describes the challenges that arise from the specific requirements of the technique, while details of the furnace design are covered in Sec. III. Section IV covers the characteristics and performance of the furnace. We present an example of an experiment carried out using the furnace in Sec. V.

\section{DESIGN REQUIREMENTS}

The requirements of the furnace, which were kept in mind during its design and are in accordance to the 3DXRD technique, are listed as follows. First, the furnace should permit rotation of the specimen around the vertical axis in order to be able to map all grains in the specimen and, at the same time, allow the high-resolution (Quantix) detector to be placed at a small distance from center of the specimen of the order of $8 \mathrm{~mm}$. For the latter, vertical distance between the beam position and top of the furnace also needs to be kept low, of the order of $14 \mathrm{~mm}$, due to space constraints dictated by the geometry of the high-resolution detector. The x-ray absorption of the furnace chamber needs to be low enough in order not to interfere with the measurements. It should be possible to achieve high heating (up to $10^{\circ} \mathrm{C} / \mathrm{s}$ ) and cooling rates (up to $30{ }^{\circ} \mathrm{C} / \mathrm{s}$ ) with accurate temperature measurement by welding at least one thermocouple to the metallic specimen. This is important to simulate in situ heat treatments of metals and ceramics, for example, thermal cycles during welding in steels. ${ }^{19}$ The temperature-time profile should be controlled accurately in order to simulate complex heat treatments that are required for the production of modern transformation-induced plasticity (TRIP) steels. Heating of the specimen (metallic or ceramic) should be uniform to reduce thermal gradients within the specimen $\left(<1{ }^{\circ} \mathrm{C}\right.$ over the beam). This is needed to certify that the measured temperature with the thermocouple is exactly the same temperature at the position of the synchrotron beam. This is important because many metallurgical processes such as diffusion of atoms depend exponentially on temperature. Environment control inside the furnace chamber should allow working in a controlled atmosphere or under vacuum. Among others, this is important for steel research because the carbon atoms can rapidly diffuse out of the steel in the presence of an oxygencontaining atmosphere, which will have a large effect on, e.g., the transition temperature of the austenite-to-ferrite phase transformation in steel. The furnace should be able to heat the specimen up to $1500{ }^{\circ} \mathrm{C}$ while keeping the temperature of high-resolution detector lower than $40{ }^{\circ} \mathrm{C}$ to prevent damage to the detector. The furnace should be able to operate at high temperatures continuously for 5 days, the typical duration of a 3DXRD beam time. The furnace design should also allow for thermal expansion of the specimen without deformation, while making sure that the specimen stands vertically straight. Deformation-free specimen is very important to study, for example, phase transformation kinetics in steels, where small deformation can lead to considerable changes in nucleation and growth rates. ${ }^{20}$

\section{FURNACE DESIGN}

Although it was envisioned to design the furnace in which the beam could access the specimen over an angular range of $360^{\circ}$, the required temperature of $1500{ }^{\circ} \mathrm{C}$ did not allow for a cylindrical design. The furnace has been designed for a free rotation of the specimen over $90^{\circ}$ on the front side and $90^{\circ}$ on the back side when the openings of the heating element dictate the maximum rotation angle. The asymmetric shape of the furnace results from the requirement of placing 


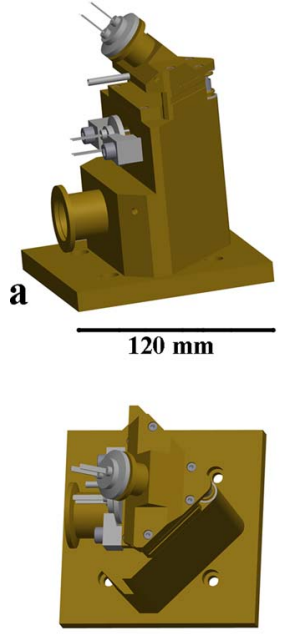

c

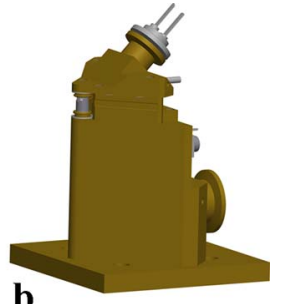

b

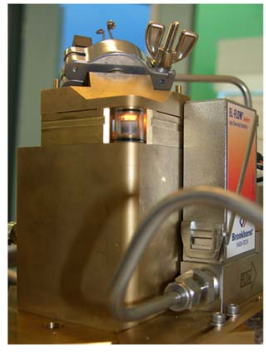

d
FIG. 2. (Color online) Schematic and real image of the 3DXRD furnace Different views are shown in (a)-(c), and the real furnace is shown in (d).

the high-resolution detector at a small distance from the specimen while allowing for rotation of the specimen. The specimen is heated by radiation (from the heating coil) and convection heating (by gas present in the specimen chamber). Schematic design and a real picture of the furnace are shown in Fig. 2. The following subsections will explain the design of different parts in detail.

\section{A. Furnace body}

The furnace base and top are made of brass $(\mathrm{Cu}: 64$ wt $\%$ and $\mathrm{Zn}: 36 \mathrm{wt} \%$ ) to have good thermal conductivity. The furnace weighs around $5 \mathrm{~kg}$ excluding vacuum assembly. The height of the furnace is approximately $15 \mathrm{~cm}$. The furnace is water cooled by means of two channels in the base and one in the top. This assists in keeping temperature variations of the furnace assembly low, thus providing good vertical stability of the specimen during experiments. This is important to certify that the same sample volume is measured during heating and cooling of the specimen. Thermal expansion of the specimen itself can be corrected for (see Sec. III C). Two vacuum feedthroughs are used to connect the thermocouples, one thermocouple through the base, on which the specimen is positioned, and one thermocouple through the top, which is welded to the top of the specimen. Heating element is also connected to the power supply through the bottom feedthrough. A channel through the top can be used as inlet for gas, regulated by a Bronkhorst digital EL-FLOW F-201CV ${ }^{\mathrm{TM}}$ electronic mass flow controller. The furnace base has a channel connected to a pressure gauge, vacuum pump, and gas outlet. The furnace base and top are connected by two supports. Cut-out view of the furnace base, supports, and top is shown in Fig. 3. Two specially designed leader pins in each support assist in positioning the top at its designed place. In order to change the specimen, furnace top can be removed with the help of two counter screws. A high precision translation table with micrometer screws is used to position the furnace in the center of rotation. This is impor-

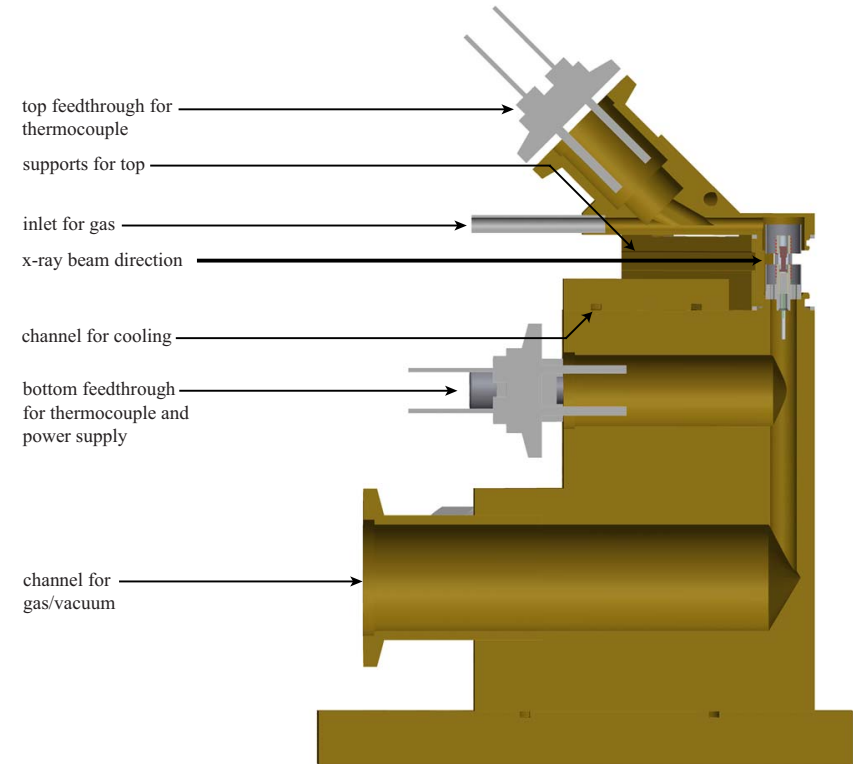

FIG. 3. (Color online) Cut-out view of the 3DXRD furnace. Different parts of the furnace are indicated. One thermocouple is spot welded on top of the sample.

tant for tomographic measurements from which the 3D structure of the metal is reconstructed.

\section{B. Specimen chamber}

The specimen chamber, shown in Fig. 4, consists of a region covered by a high purity $(99.995 \%)$ quartz tube ( $1 \mathrm{~mm}$ thick to minimize background). To achieve optimum sealing of the specimen chamber, polymer o-rings are used to connect the quartz tube to the furnace base and top. Since the o-rings are less than $6 \mathrm{~mm}$ away from the heating element heated to $1500{ }^{\circ} \mathrm{C}$, the o-rings also get heated to high temperatures. To ensure proper service, Kalrez ${ }^{\circledR}$ o-rings are used, which can withstand temperatures of up to $317^{\circ} \mathrm{C}$. Helium present in the specimen chamber heats the specimen very

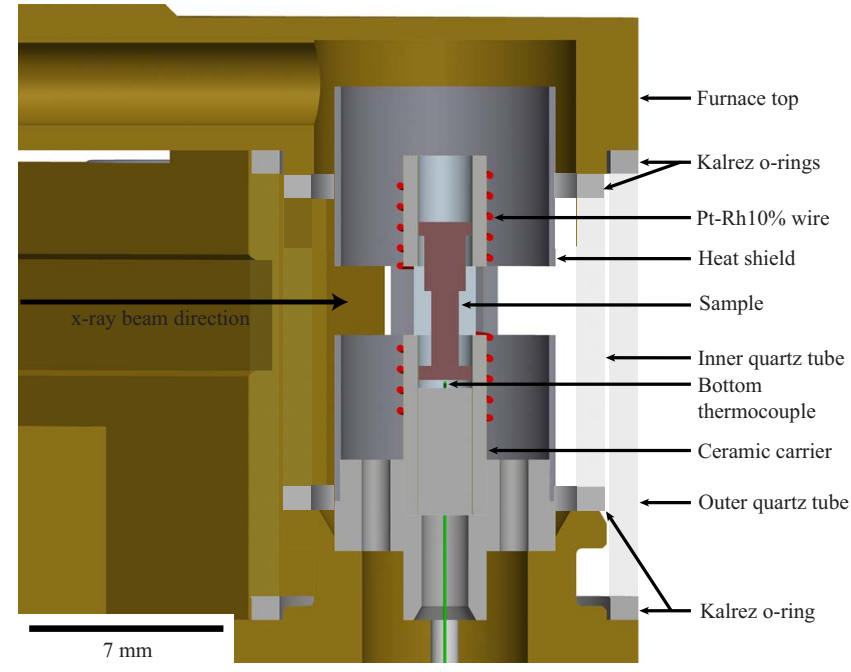

FIG. 4. (Color online) Cut-out view of the specimen chamber. The x-ray beam direction and location of specimen are indicated. For changing the specimen, furnace top is removed, and the specimen is dropped onto the bottom thermocouple. Geometry of the specimen can be seen with the step due to change in diameter visible. 
effectively by convection. However, it also heats up the o-rings to high temperatures. Hence, in case of long annealing times $(>5 \mathrm{~h})$ at high temperatures $\left(>800^{\circ} \mathrm{C}\right)$, a different setup has to be used. An additional quartz tube with two o-rings is placed on the inside of the original quartz tube. The o-rings for this quartz tube are even closer to the high temperatures and start to degrade quite soon. At the same time, they act as a barrier for helium access to the outer o-rings and thus keep temperature of the outer o-rings low, resulting in longer vacuum stability. The construction with the double quartz window simultaneously acts as a heat shield to maintain the room temperature just outside the furnace where the expensive high-resolution detector is located. The background signal during synchrotron radiation measurements from the quartz tubes is low for $\mathrm{x}$-ray energies usually used for studies of metals, i.e., $50 \mathrm{keV}$ or more.

\section{Atmosphere control}

Before heating up, the specimen chamber can be alternatingly purged with helium and kept under vacuum to get rid of air remaining in the specimen chamber. The heat shield, made of pure tantalum or titanium, has two windows for the incoming and transmitted/diffracted beams and is put around the heating coil and the specimen in order to minimize heat losses to the surroundings. It simultaneously acts as a getter at high temperatures for any oxygen left behind. The furnace can be operated under different specimen environments ranging from low pressure (up to $10^{-5}$ mbar) to controlled gases at desired pressure and also in air. Sealing of the specimen chamber was checked using a helium leak detector before, during, and after heat treatment (isothermal annealing at $1100{ }^{\circ} \mathrm{C}$ for $3 \mathrm{~h}$ ) to check the degradation of the o-rings. The rate of helium leakage was found to be lower than $10^{-9} \mathrm{mbar} 1 / \mathrm{s}$. No change in leakage rate was detected after heat treatment, showing minimal or no damage to the outer o-rings.

The specimen is cylindrical in shape with a change in diameter from 1 to $1.5 \mathrm{~mm}$. During the experiment, the location of interaction volume of the specimen and $\mathrm{x}$-rays can be determined by scanning for the abrupt change in diameter of the specimen

\section{Heating element and specimen holder}

Although heating can be carried out by various methods such as induction heating, laser heating, etc., the special requirements (such as low thermal gradient, heating of ceramic specimen, etc.) of the furnace allowed for resistance heating only. In order to minimize thermal gradients in the specimen, heating is done by passing dc current through a coil ( $\mathrm{Pt}-\mathrm{Rh}$ : $10 \%$ and $\phi=0.25 \mathrm{~mm})$ wound on a ceramic carrier $\left(\mathrm{Al}_{2} \mathrm{O}_{3}\right.$ tube, inner diameter $\phi=2 \mathrm{~mm}$ ) directly around the specimen (Fig. 4). The Pt-Rh wire is chemically inert and can be heated to temperatures of up to $1750{ }^{\circ} \mathrm{C}$. The specimen is made out of a cylinder. The diameter changes three times abruptly over the length of the specimen (see Fig. 4). At the top and bottom of the specimen, the diameter is the largest and just fits into the cylindrical ceramic carrier in order to position the specimen vertically straight and at the same time allow for free thermal expansion of the specimen in order to avoid any deformation in the specimen. At the location of the smallest diameter, the 3DXRD measurements are performed. The intermediate diameter is present to serve as a reference point, which can be found with the synchrotron beam by monitoring the change in intensity of the primary beam, which will be more absorbed in the thicker part of the specimen. From the step edge the specimen is moved with respect to the beam to the measurement location. In this way, the location where the synchrotron beam interacts with the specimen is exactly known. This gives the opportunity to perform ex situ electron microscopy and EBSD measurements after the synchrotron radiation measurements at exactly the same location as the synchrotron diffraction measurements were performed.

The specimen is lowered from top and sits on the bottom thermocouple. S-type thermocouples $(\phi=0.15 \mathrm{~mm})$ are used for temperature recording. This was chosen for two reasons: (a) S-type thermocouples are the most accurate at higher temperatures and (b) thin thermocouple wires help in minimizing the time lag for temperature readout and do not act as heat sink. The inner diameter of the ceramic tube is chosen to allow for expansion of the specimen at higher temperatures. For minimizing heat loss to the surroundings, the volume of the specimen is kept small $\left(8.5 \mathrm{~mm}^{3}\right)$, which allows for low power requirement and also high heating and cooling rates. Small specimen volumes are sufficient for many investigations because many of the microstructural changes of polycrystalline materials are in the region from a few nanometer up to a millimeter.

\section{Furnace control}

Furnace control is achieved by using Eurotherm ${ }^{\circledR} 3504$ controller connected to a computer. Process modeling can be done on the controller or via the ITOOLS ${ }^{\circledR}$ program. For temperature control, either both or one of the two thermocouples at bottom and top of the specimen can be used. In normal operation, temperature is controlled using the top thermocouple welded directly on top of the sample to avoid inaccuracies due to possibly bad contact between sample and the bottom thermocouple. The heat treatments and gas flow can be programmed in the software. Real-time recording of different parameters such as temperature on top and bottom of the specimen, gas flow conditions used, programmed parameters, etc. can be carried out.

\section{FURNACE CHARACTERISTICS AND PERFORMANCE}

Due to small size of the specimen, a very wide range of heating (up to $20{ }^{\circ} \mathrm{C} / \mathrm{s}$ ) $/$ cooling rates can be achieved. Although quenching by helium can also be carried out, in most cases the specimen can cool down at a rate of $30{ }^{\circ} \mathrm{C} / \mathrm{s}$ just by switching off the power supply, with higher cooling rates possible by using a continuous helium flow. Only $35 \mathrm{~W}$ of power is required to heat the specimen up to $1000{ }^{\circ} \mathrm{C}$, with the limit for maximum allowable power of up to $80 \mathrm{~W}$. The furnace can go to temperatures of up to $1500{ }^{\circ} \mathrm{C}$. This has 


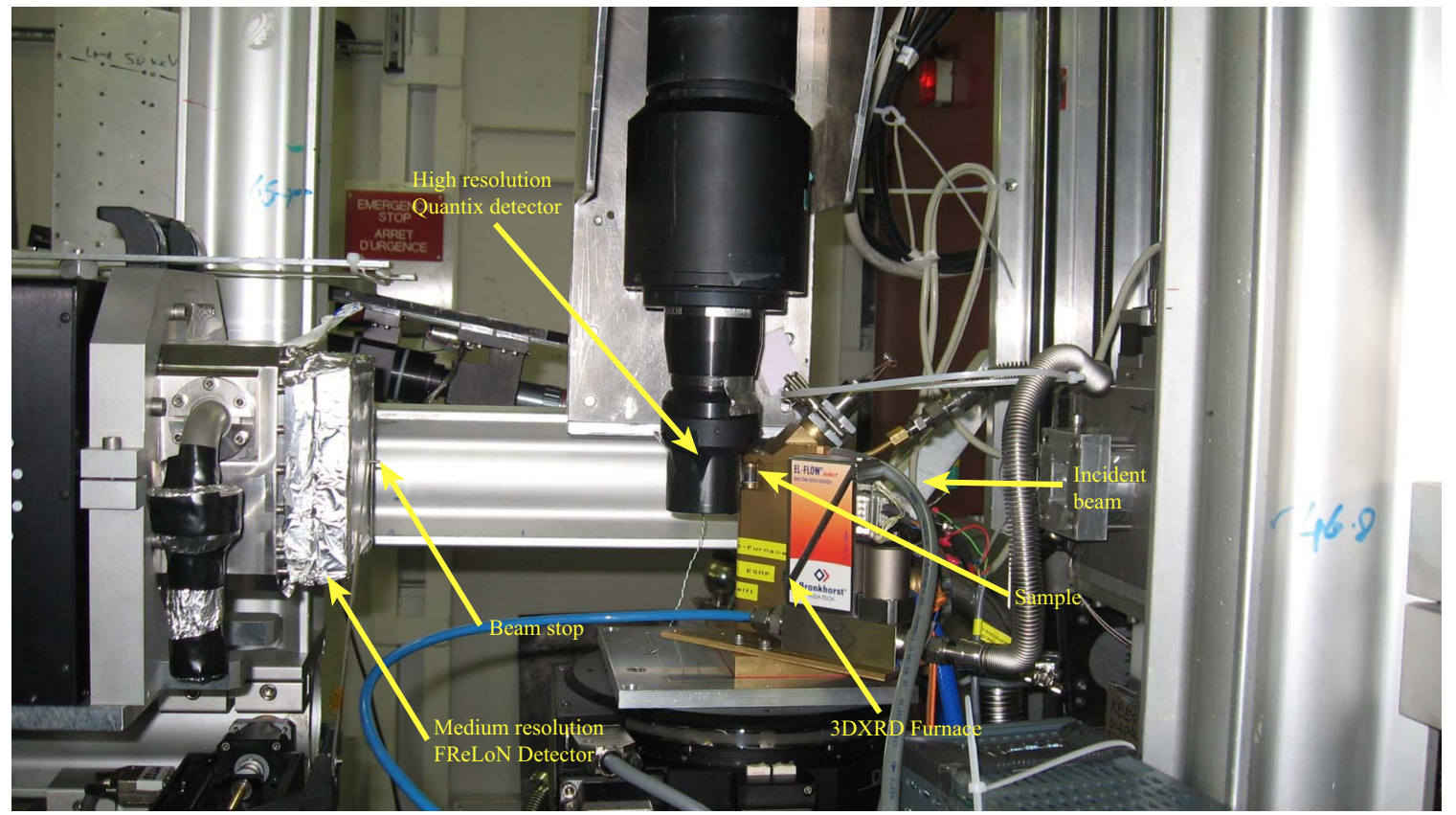

FIG. 5. (Color online) Photograph of the 3DXRD furnace installed at beam line ID11 at the ESRF. The furnace is mounted on a rotation and translation table for positioning in the beam. Location of the high-resolution (Quantix) and medium resolution (FReLoN) detectors is indicated. The high-resolution Quantix detector has a slit for primary beam and is semitransparent.

been tested by melting a steel sample, which had a melting point of above $1500{ }^{\circ} \mathrm{C}$. The use of a proportional-integralderivative controller such as Eurotherm ${ }^{\circledR} 3504$ allows for accurate temperature control and stabilization. For the temperature constraint arising from close proximity of the highresolution detector, with the specimen at $1000{ }^{\circ} \mathrm{C}$, the temperature at a distance of $10 \mathrm{~mm}$ from center of the specimen reaches around $58{ }^{\circ} \mathrm{C}$ with only the outer quartz tube present. This is higher than the allowable limit of $40{ }^{\circ} \mathrm{C}$ for the high-resolution detector. This temperature can be brought down to around $26{ }^{\circ} \mathrm{C}$ by using a cooling fan outside the furnace. However, in order to reduce heating by radiation, a reflective aluminum foil $0.8 \mu \mathrm{m}$ in thickness can be placed in between the two quartz tubes. This is important while going to temperatures of above $1200{ }^{\circ} \mathrm{C}$ due to increased radiation. The temperature gradient in the specimen, measured during a thermal cycle of continuous heating from room temperature to $1000{ }^{\circ} \mathrm{C}$ in $2 \mathrm{~min}$, holding isothermally at $1000{ }^{\circ} \mathrm{C}$ for $10 \mathrm{~min}$ and continuous cooling to room temperature in $5 \mathrm{~min}$, was found to be less than $0.5{ }^{\circ} \mathrm{C}$ between top and middle of the specimen.

\section{EXPERIMENTS}

3DXRD experiments on the furnace were carried out in December 2008 and July 2009 at beam line ID11 at ESRF. Figure 5 shows the furnace installed at beam line ID11 of ESRF. The setup shown combines the use of both highresolution (Quantix) and medium resolution $\left[\mathrm{FReLon}^{21}\right.$ detectors simultaneously in which the high-resolution detector is partially transparent. Quantix also has a slit to allow the primary x-ray beam through. Figures 6(a) and 6(b) show two examples of diffraction patterns recorded simultaneously using Quantix and FReLoN detectors, respectively. The specimen (steel alloy of composition $\mathrm{Fe}-0.1$ wt $\% \mathrm{C}-1$ wt \%

$\mathrm{Mn}$ ) was at $780^{\circ} \mathrm{C}$ at the time of measurement, with Quantix being $10 \mathrm{~mm}$ away from center of the specimen and FReLoN $225 \mathrm{~mm}$ away. With cooling achieved using a fan, the measured temperature in front of Quantix detector was $24{ }^{\circ} \mathrm{C}$. A beam size of $1000 \times 500 \mu \mathrm{m}^{2}$ was used. The $\mathrm{x}$-ray energy was $78.395 \mathrm{keV}$, the sample was rotated over an angle of $0.3^{\circ}$ during each exposure, and exposure time was equal to $0.2 \mathrm{~s}$. The position of the grains in the sample strongly influences the location of diffraction spots on the highresolution Quantix detector as shown in Fig. 6(a) because the Quantix detector is so close the specimen. ${ }^{22}$ In the case of the FReLoN detector, the position of diffraction spots is not influenced by the position of diffracting grains in specimen anymore because the FReLoN detector is positioned at a distance of typically $250 \mathrm{~mm}$ away from the specimen. This is why diffraction rings cannot be observed in Fig. 6(a).

Figure 7 shows a thermal cycle during welding carried out on a TRIP steel specimen [composition (wt, \%) - $0.19 \%$ $\mathrm{C}, 1.63 \% \mathrm{Mn}, 1.1 \% \mathrm{Al}$, and rest, $\mathrm{Fe}]$ and also examples of diffraction patterns recorded at different stages during the heat treatment. The specimen was heated from room temperature [Fig. $7(\mathrm{a})]$ at a rate of $15{ }^{\circ} \mathrm{C} / \mathrm{s}$ to $1000{ }^{\circ} \mathrm{C}$ [Fig.

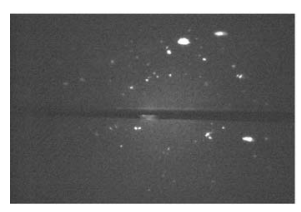

a

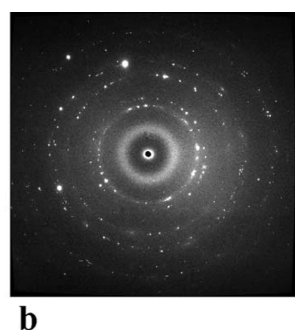

FIG. 6. Examples of diffraction patterns recorded from (a) high-resolution Quantix detector and (b) medium resolution FReLoN detector simultaneously. 

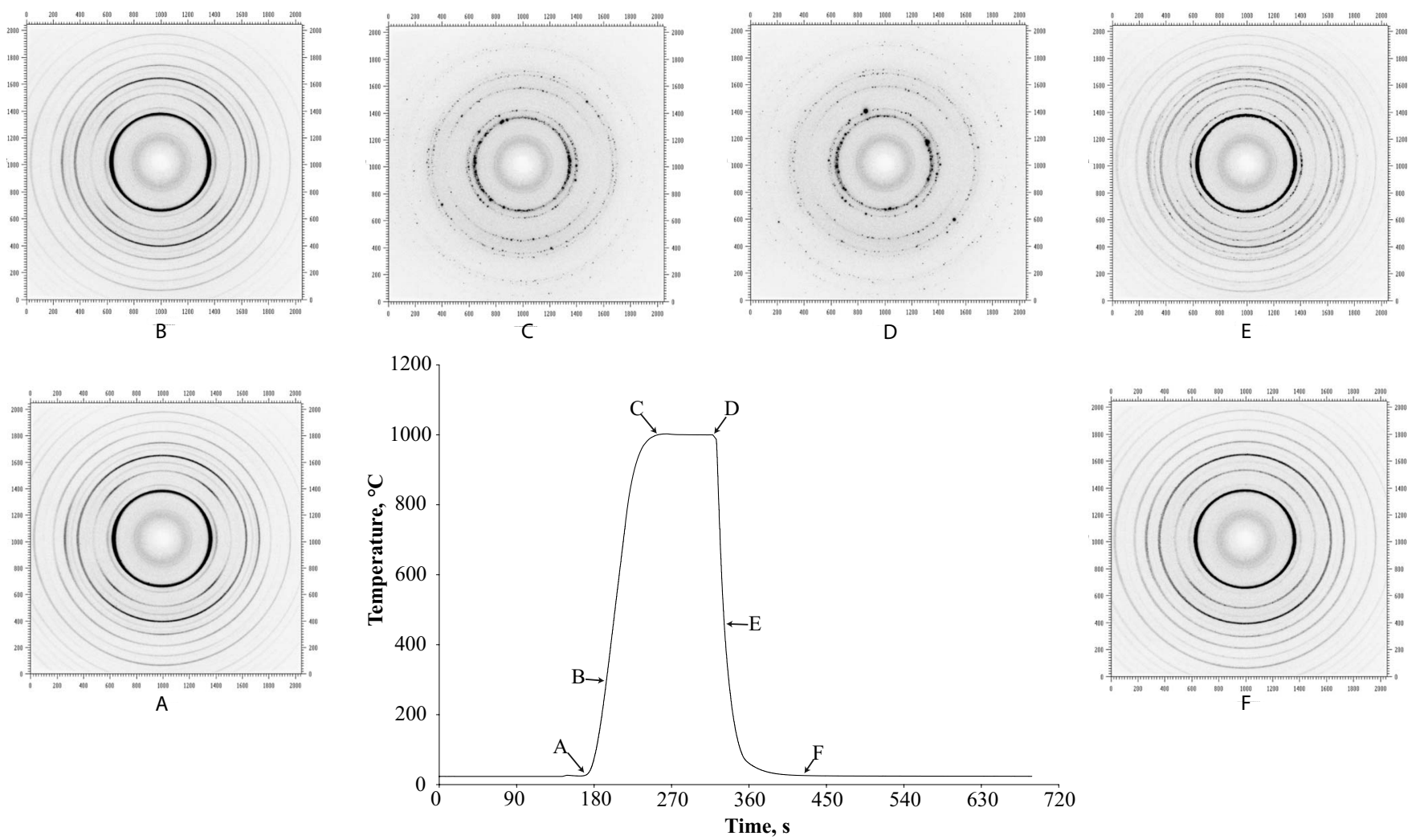

FIG. 7. Example of diffraction patterns recorded during welding thermal cycle on a TRIP steel. A-diffraction pattern recorded from the initial TRIP microstructure. B-diffraction patterns recorded during heating. C-diffraction pattern recorded at the beginning of isothermal holding. D-diffraction pattern recorded at the end of isothermal holding. E-diffraction pattern recorded during quenching. F-diffraction pattern of the final microstructure at room temperature. Presence of both austenite and ferrite diffraction spots can be seen in the diffraction images.

7(b)], isothermally held at $1000{ }^{\circ} \mathrm{C}$ for $60 \mathrm{~s}$ [Figs. 7(c) and 7(d)], and quenched [Fig. 7(e)] at an average rate of $15^{\circ} \mathrm{C} / \mathrm{s}$ to room temperature [Fig. 7(f)]. The maximum cooling rate was $36{ }^{\circ} \mathrm{C} / \mathrm{s}$ from 1000 to $600{ }^{\circ} \mathrm{C}$. At lower temperatures the cooling rate was kept lower to simulate welding conditions. ${ }^{19}$ Diffraction patterns were recorded every $0.3 \mathrm{~s}$.

During the experiments, stability of the setup was checked by carrying out various experiments on a single specimen for $32 \mathrm{~h}$. The specimen was kept at $900{ }^{\circ} \mathrm{C}$ for a total of $12 \mathrm{~h}$ and was heated and cooled down from and to $600{ }^{\circ} \mathrm{C}$ four times. At the end of experiments, no oxidation was observed on the sample, and the specimen chamber was still leak tight. This shows that the furnace is ideal for long experiments without the need of changing the sample, while the beam time was wasted in changing samples.

\section{FUTURE DEVELOPMENTS}

In the future, the furnace can be modified to achieve a field of view of $360^{\circ}$ (except for a shadow of the heating coil) by removing the ceramic carrier and the heating coil wound on it (see Fig. 4 for details). These will be replaced by only a heating coil of Pt-Rh $10 \%$, the top and its supports will be removed, and the furnace chamber will be covered with closed quartz. This setup would be very useful for techniques such as DCT, which requires a full $360^{\circ}$ rotation around the sample axis. However, due to reduced efficiency of heating from the wire, the maximum specimen tempera- ture in this setup that can be reached would be limited to around $900{ }^{\circ} \mathrm{C}$ due to the absence of a ceramic carrier for heat transfer to the specimen.

In addition, the furnace chamber can also be modified to fit the SAXS requirements. In the current setup, while operating at low $\mathrm{x}$-ray energies $(<20 \mathrm{keV})$, absorption and scattering signal from the quartz tubes can become significant. In such cases, the quartz tube will be replaced by a steel tube with two slits for the incident beam and scattered signal. The two slits will be covered with Mica foils (to ensure minimum absorption or scattering signal from the foils) glued to the outside of the steel tube in order to achieve sealing. However, the maximum specimen temperature in this setup would also be limited by the limit of high temperature stability of the Mica foils.

\section{CONCLUSIONS}

We have presented a furnace designed for carrying out synchrotron radiation experiments for polycrystalline materials research. The furnace combines various requirements of materials research, such as fast heating $\left(20^{\circ} \mathrm{C} / \mathrm{s}\right)$ and cooling rates $\left(30^{\circ} \mathrm{C} / \mathrm{s}\right)$, high operating temperatures $\left(1500{ }^{\circ} \mathrm{C}\right)$, low temperature gradients across the sample $\left(<1{ }^{\circ} \mathrm{C}\right)$, accurate temperature control, and control of specimen environment (vacuum of up to $10^{-5}$ mbar or gas filled), with the requirements of synchrotron radiation techniques (for example, 3DXRD) such as rotation of specimen over a wide angular range $\left(90^{\circ}\right)$, space and temperature constraints from 
detectors and low x-ray absorption of the furnace chamber. We have illustrated, with the help of examples, the various strengths of the furnace. Its unique characteristics open up new fields of research in materials science such as studies of phase transformation kinetics and simulation of welding conditions in metals. Although designed for metals research using the 3DXRD technique, the furnace is expected to prove to be an invaluable tool for ceramics research and be applied to other synchrotron radiation techniques as well.

\section{ACKNOWLEDGMENTS}

The authors would like to acknowledge the contribution of Ben Schelen, Mario van der Wel, Rik van der Hoeven, and Marco Pelle from DEMO, TU Delft, for the design and manufacture of the furnace. We acknowledge the help of Juriaan van Slingerland, Hiske Landheer, and Emine Gözde Dere from MSE, TU Delft, in helping out with the characterization of the furnace. We also thank Niels van Dijk, TU Delft, Larry Margulies and Erik Lauridsen, RIS $\varnothing$, and Jonathan Wright and Gavin Vaughan, ESRF, for their inputs in the design of the furnace. We thank ESRF for granting beam time under long-term project MA-333 and the Dutch technology foundation STW for their financial contribution to the project.

${ }^{1}$ J. Baruchel, J. Y. Buffiere, P. Cloetens, M. Di Michiel, E. Ferrie, W. Ludwig, E. Maire, and L. Salvo, Scr. Mater. 55, 41 (2006).

${ }^{2}$ J. Baruchel, P. Bleuet, A. Bravin, P. Coan, E. Lima, A. Madsen, W. Ludwig, P. Pernot, and J. Susini, C. R. Phys. 9, 624 (2008).

${ }^{3}$ G. E. Ice and B. C. Larson, Adv. Eng. Mater. 2, 643 (2000).
${ }^{4}$ B. C. Larson, W. Yang, G. E. Ice, J. D. Budai, and J. Z. Tischler, Nature (London) 415, 887 (2002).

${ }^{5}$ D. J. Jensen, E. M. Lauridsen, L. Margulies, H. F. Poulsen, S. Schmidt, H. O. Sorensen, and G. B. M. Vaughan, Mater. Today 9, 18 (2006).

${ }^{6}$ D. J. Jensen, S. E. Offerman, and J. Sietsma, MRS Bull. 33, 621 (2008).

${ }^{7}$ S. E. Offerman, N. H. van Dijk, J. Sietsma, S. Grigull, E. M. Lauridsen, L. Margulies, H. F. Poulsen, M. T. Rekveldt, and S. van der Zwaag, Science 298, 1003 (2002).

${ }^{8}$ E. M. Lauridsen, D. J. Jensen, H. F. Poulsen, and U. Lienert, Scr. Mater. 43, 561 (2000).

${ }^{9}$ A. King, G. Johnson, D. Engelberg, W. Ludwig, and J. Marrow, Science 321, 382 (2008).

${ }^{10}$ W. Ludwig, S. Schmidt, E. M. Lauridsen, and H. F. Poulsen, J. Appl. Crystallogr. 41, 302 (2008).

${ }^{11}$ G. Johnson, A. King, M. G. Honnicke, J. Marrow, and W. Ludwig, J. Appl. Crystallogr. 41, 310 (2008).

${ }^{12}$ S. Schmidt, S. F. Nielsen, C. Gundlach, L. Margulies, X. Huang, and D. J. Jensen, Science 305, 229 (2004).

${ }^{13}$ L. Margulies, G. Winther, and H. F. Poulsen, Science 291, 2392 (2001).

${ }^{14}$ B. Jakobsen, H. F. Poulsen, U. Lienert, J. Almer, S. D. Shastri, H. O. Sorensen, C. Gundlach, and W. Pantleon, Science 312, 889 (2006).

${ }^{15}$ A. D. Rollett, S. B. Lee, R. Campman, and G. S. Rohrer, Annu. Rev. Mater. Res. 37, 627 (2007).

${ }^{16}$ L. Margulies, M. J. Kramer, R. W. McCallum, S. Kycia, D. R. Haeffner, J. C. Lang, and A. I. Goldman, Rev. Sci. Instrum. 70, 3554 (1999).

${ }^{17}$ D. Bellet, B. Gorges, A. Dallery, P. Bernard, E. Pereiro, and J. Baruchel, J. Appl. Crystallogr. 36, 366 (2003).

${ }^{18}$ H. G. Brokmeier, S. B. Yi, N. J. Park, and J. Homeyer, Diffus. Defect Data, Pt. A 105, 55 (2005).

${ }^{19}$ M. Amirthalingam, M. Hermans, and I. Richardson, Metall. Mater. Trans. A 40, 901 (2009).

${ }^{20}$ H. Landheer, S. E. Offerman, R. H. Petrov, and L. A. I. Kestens, Acta Mater. 57, 1486 (2009).

${ }^{21}$ J. C. Labiche, O. Mathon, S. Pascarelli, M. A. Newton, G. G. Ferre, C. Curfs, G. Vaughan, A. Homs, and D. F. Carreiras, Rev. Sci. Instrum. 78, 091301 (2007).

${ }^{22}$ H. F. Poulsen and S. Schmidt, J. Appl. Crystallogr. 36, 319 (2003). 